\title{
SPIRIT OF THE PLACE: EVOLUTIONAND TRANSFORMATION OF ISTANBUL CHOWK, LAHORE
}

\author{
Faisal Sajjad* \\ Neelum Naz** \\ Ghulam Abbas Anjum***
}

\begin{abstract}
The main focus of this research is the study of Istanbul Chowk, Lahore from the perspective of its historical evolution during the British Colonial period and post partition transformation. This area was known as 'Exhibition Road' during the British times and Patras Bukhari Chowk after partition, named after the famous writer and the former principal of Government College of Lahore. The name 'Istanbul Chowk' was given later, named after the city of Istanbul in Turkey. This is the first chowk or public space on the west end of the Mall Road, institutional in character and an example of $19^{\text {th }}$ century colonial planning. The Mall Road is named after the central street of London, which leads from Buckingham Palace to Trafalgar Square. Ceremonial royal processions pass down the Mall. This road was planned in 1851 by Col. Napier to connect the city with the new cantonment that was 7 miles to the east. The theoretical aspect of 'Colonial spatial imagination' is discussed in connection with the design of this unified urban space in its form and character. The intangible aspects of urban culture contributing towards the construction of 'spirit of place' over a period of time extending into the post partition era have also been explored. This research paper also studies the post partition gradual transformation of this place and identifies the spatial changes and loss of urban heritage which played an important role in forming the identity and spirit of this place.
\end{abstract}

Keywords: Place making, colonial spatial imagination, genius loci, palimpsest, Lahore

\section{RESEARCH METHODOLOGY}

The research methodology encompasses a number of methods. The historical context of the area in general and Istanbul Chowk in particular is established with the help of a review of archival documents and references are drawn from various relevant sources.
Very few scholars have written about Lahore's urban history and theory. William Glover (2008) is one who has discussed Colonial spatial imagination and planning of Lahore in his book "Making Lahore Modern". The other author who has theorised the aspect of people's association with public places, with Lahore as a case study is Suvorova (2011) in her book "Lahore: Topophilia of Space and Place".

The physical planning of the space around Istanbul Chowk, its description and analysis, pertaining to the quantifiable aspect of urban space including layout, geometry and proximity is researched with the help of archival cartographic references.

The qualitative aspect including sense of space, sense of enclosure, architectural character and environment has been constructed through the study and analysis of the archival photographs.

The intangible aspect mentioned as the 'spirit of place' is discussed with the help of literary references about this place in which a connection can be established between the physical space and life in the area, transforming it into an identifiable place with a distinct culture. These references are also available from the literature available from post partition and are helpful in establishing the transformation in the culture of this place.

A comparison is drawn between the formative period and the current condition of Istanbul Chowk to identify and study the spatial transformation and its impact on the spatial integrity and urban culture.

\section{INTRODUCTION}

Planned public spaces are commonly found in the heart of most historical cities. In Pakistan, the term "square" is synonymous with 'chowk'. Public spaces house political,

* Faisal Sajjad, Associate Professor, Department of Architecture, NCA, Lahore

** Dr. Neelum Naz, Professor, Department of Architecture, University of Engineering \& Technology, Lahore

*** Dr. Ghulam Abbas Anjum, Prof. and Dean, Department of Architecture, University of Engineering \& Technology, Lahore

Journal of Research in Architecture and Planning: Vol. 18, 2015 (First Issue) 
economic and cultural life. They indicate a city designed for humans as these spaces are mostly pedestrian. These spaces because of their historicity, become iconic centers and form the identity of a city. It is the transformation from a public space to a public place that defines the collective memory of a city. This is the phenomenon of place making which revolves around the notion of an abstract space being connected into a recognizable place in the city.

Lahore is one of the most important cities of the sub-continent from both strategic and cultural perspectives. It was always at the crossroads of civilizations. Many foreign invaders (Aryans, Greeks, Arabs, Afghans and Central Asian) passed through this area and left their impressions on the city. It was the capital of the Mughal Empire during the reign of Akbar, the third Mughal Emperor (1556-1605). The city was ruled by the Sikhs and later by the British. This cultural layering has rendered Lahore like a palimpsest.

Lahore has a rich public life that has evolved around the public spaces like the Friday Book Bazaar in Chowk Masjid Wazir Khan, the cultural environment of Chowk Neela Gumbad, the educational environment of Chowk Istanbul and the political character of Charing Cross, named after a square in London and renamed Faisal Square after King Faisal of Saudi Arabia in 1973 at the time of Islamic Summit Conference. The city of Lahore has seen the evolution and transformation of its public spaces, both spatially and culturally.

In this reference, the Colonial period is of specific importance since it was the beginning of modern planning in Lahore. Punjab went under the Company Rule (The British East India Company) in 1849 and was finally annexed to the Crown (The British Empire) in 1858. Under the Company's rule, architecture and planning was limited to retrofitting and improvement of services. It was under the Crown that the new ideas and theories of urban design were implemented outside the walled city of Lahore.

In the case of Istanbul Chowk it was strategic incremental addition of institutional buildings that defined the urban space. The nature and use of these buildings was of prime importance because without any confusion the British planners conceived this place as cultural, educational and institutional in nature. Even the sculptures and monuments added to this character. This gave the area a distinctive sense of place and character.

\section{ISTANBUL CHOWK: EVOLUTION AND LAYOUT}

The British initially developed the Old Mall Road along the north-south axis with the old cantonment establishment in the present day Anarkali area (area of Lahore outside the walled city that served as the first British army Cantonment, later on it developed as a bazaar). In 1851 the cantonment was shifted to the Mian Mir area (named after the Mughal Period Saint Hazrat Mian Mir), seven miles to the east of the current location and the present Mall Road was planned to connect the city with the new Cantonment. Along this road new spatial typologies in the form of public spaces were introduced. One of these was the Exhibition Road area (Istanbul Chowk), which was a public space with a defined character. This is the oldest planned area on the Mall. Its development took place between 1860 and 1905 and it formed the west end of the Mall, ending at the Nasir Bagh. This garden was the terminating axis of the Mall on the west end. It was initially known as Bandstand Garden, then as Municipal Garden after the construction of Victoria Jubilee Hall, it was also known as Gol Bagh because of its roughly round shape and Chowk. After partition it was renamed Nasir Bagh after Jamal Abdul Nasir of Egypt. The Istanbul chowk has been renamed several times too. It was initially called Exhibition Road area, after 1876 its name was changed to Upper Mall, post partition it was renamed as Patras Bukhari Chowk after the famous writer and Principal of Government College Lahore, and finally it was named 'Istanbul Chowk' to commemorate Pak-Turk friendship (Figure 1).

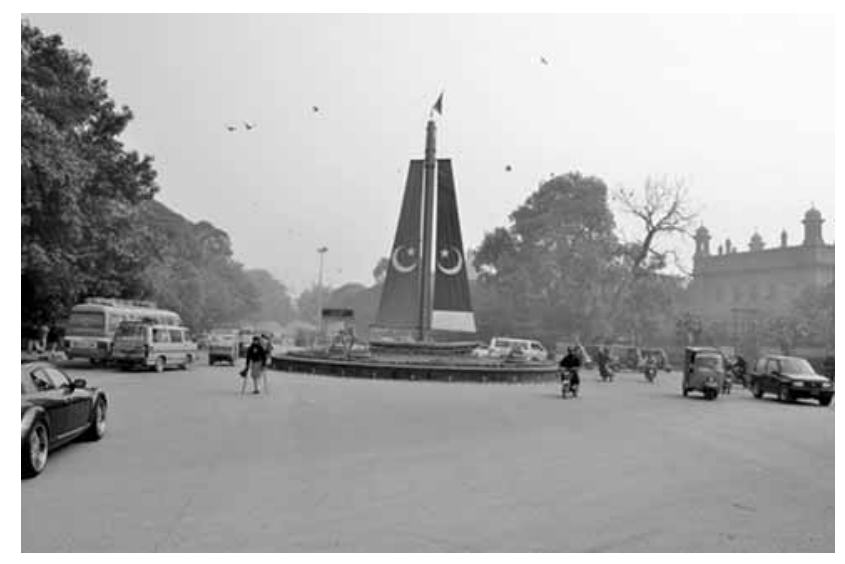

Figure 1: Istanbul Chowk

Source: www.googleimages.com accessed 23-6-14 
Goulding and Thornton (1924: 52) mentions the stretch of Mall between Anarkali and Gol Bagh as the Exhibition Road area. He writes that this was built to commemorate the inauguration of the Punjab Exhibition Building in 1864. This building was constructed to house the exhibition of the crafts of Punjab. It was later converted into a market and renamed as Tollinton Market.

In the 1920s map (Figure 2) the Exhibition Road is annotated as Upper Mall and is of varying width throughout. The Anarkali Road crossing the Mall Road divides the institutional zone and the commercial zone. The Mall is wider in front of the Tollinton Market with a rectangular green space across and is narrower in front of the Museum, but the presence of the fenceless semi-circular green spaces with carriageways in front of the Museum and the Punjab University Senate Hall opposite the Museum has given a spatial definition to this area. Between the Museum and the Tollinton Market the winding Library Road joins the Mall. An irregular ellipse in plan, Nasir Bagh is the terminating axis of the Mall and of this area.

There is an incident mentioned by Goulding and Thornton (1924) that describes the road widening and up gradation project in the area and the keen interest the officers of that time took in the planning and their concern for the environment of the area:

"later still the whole length of the Mall was remodelled on its present lines under the personal supervision of the late Mr DuCane Smythe, Chief Engineer, who in turn, was supervised by the then Lieutenant - Governor, Sir Charles Rivaz. It was nothing unusual to meet, on a winter's morning, these two high officials in earnest consultation by the roadside. On one occasion the writer saw the Chief Engineer kneeling on the ground with a measuring tape in his hands, while on another the Lieutenant-Governor, who never allowed the felling of a tree if it could possibly be avoided, was personally superintending the marking of certain roadside trees which had to come down when the Mall was being realigned and widened opposite the Mayo School of Art." (Goulding and Thornton 1924: 47-48)

Powell et.al (1917: 30) writes in one of his reports about urban improvements in Lahore. He mentions that the area of Anarkali connecting McLagan Road and the Museum complex is in urgent need of repair and up gradation and a cost effective proposal is needed. Thus, the locality was always considered a prime urban space that needed to be developed with a certain vision.

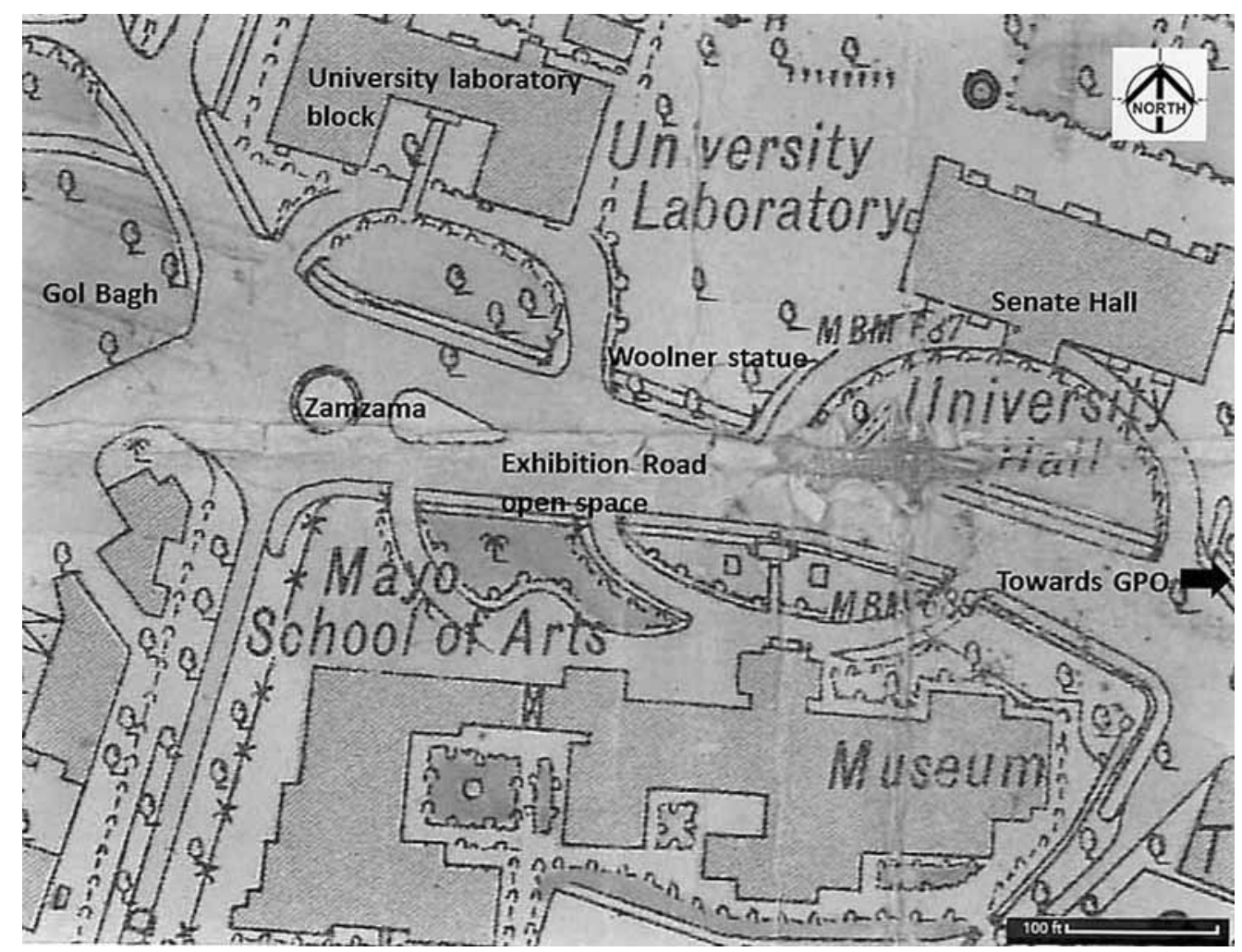

Figure 2: Map of Istanbul Chowk, 1927 Source: Rehman (2013) 


\section{MAIN BUILDINGS AROUND THE ISTANBUL CHOWK}

The addition of buildings to the Istanbul Chowk was incremental. The south side of the road was developed first because this entire stretch comprised of exhibition, museum and crafts school buildings and north facing orientation was more suited to these functions (Figure 2). The entire stretch on north side of the road is the Punjab University campus.

\section{Tollington Market}

The first building to come up was the Punjab Exhibition Building in 1864. Though it does not form a part of Istanbul Chowk, still it serves like an introduction to the area and sets the tone. The second building was the Mayo School of Arts that was completed in 1882. This was a planned building because erecting a crafts school along with an exhibition building was a typical Victorian concept. The new Museum was built in 1893. This completed the complex of the crafts school and the museum. The Town Hall was built in 1890. The last building to come up was the Punjab University Senate Hall, which was built in 1905 . The architectural character of these buildings is peculiar to Lahore. With the exception of Punjab Exhibition Building (Figure 3) the rest of the buildings are in red brick giving a uniform architectural character to the area that is well complemented by the leafy trees. The Punjab Exhibition Building was renamed Tollington Market after the construction of the Lahore Museum.

In the archival photograph (Figure 3) of the inauguration of Punjab Industrial Crafts Exhibition in 1864 one can see the newly finished building with almost nothing around it. It is a structure with Gothic detailing.

Kipling and Thornton (1860: 73) write about this building mentioning it as the Central Museum, not to be confused with the Lahore Museum which was constructed much later. They have written that this structure was not planned as a permanent one; it was rather a building put up for the exhibition on urgent basis and to be dismantled later.

A recent success is the stopping of near demolition of Tollinton Market through advocacy a group of professional architects. It was restored and reconstructed close to the 1864 form (Figure 4); however with the present alignment of the Mall, it was impossible to reconstruct the original colonnade and extended porticos of the Tollinton as it would have covered one lane of the present road. The building is presently being used as the Lahore City Heritage Museum.

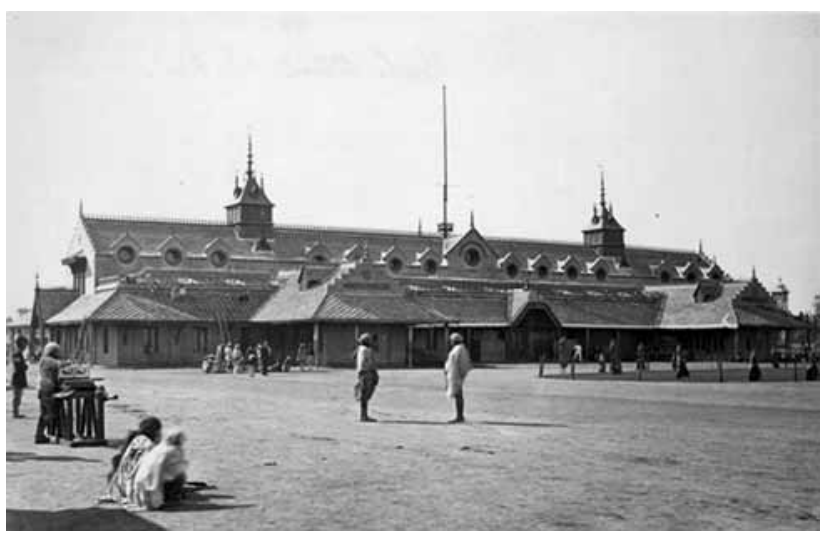

Figure 3: Punjab Exhibition Building 1864 Source: Aijazuddin (2003)

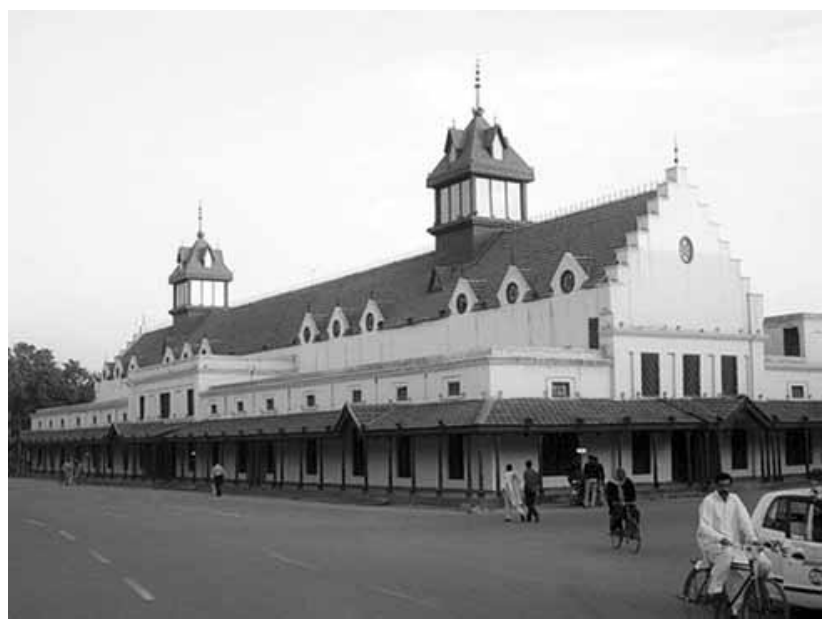

Figure 4: Tollinton Market after restoration

\section{Jubilee Museum (Lahore Museum) and Mayo School of Industrial Arts (National College of Arts)}

There is also a mention of the Museum Complex in Walker (1989:247), according to which the complex housed a museum and an art college and was planned with the provincial budget on the occasion of golden jubilee of the rule of Queen Victoria in 1887. It was completed in 1893. The Museum is an eclectic domed structure in brick with entrance pavilion in marble (Figure 5).

Latif (1892: 273) mentions that the Museum Complex was designed by the then Principal of the School, John Lockwood Kipling and Bhai Ram Singh, and the project was supervised by the Executive Engineer Ganga Ram. 


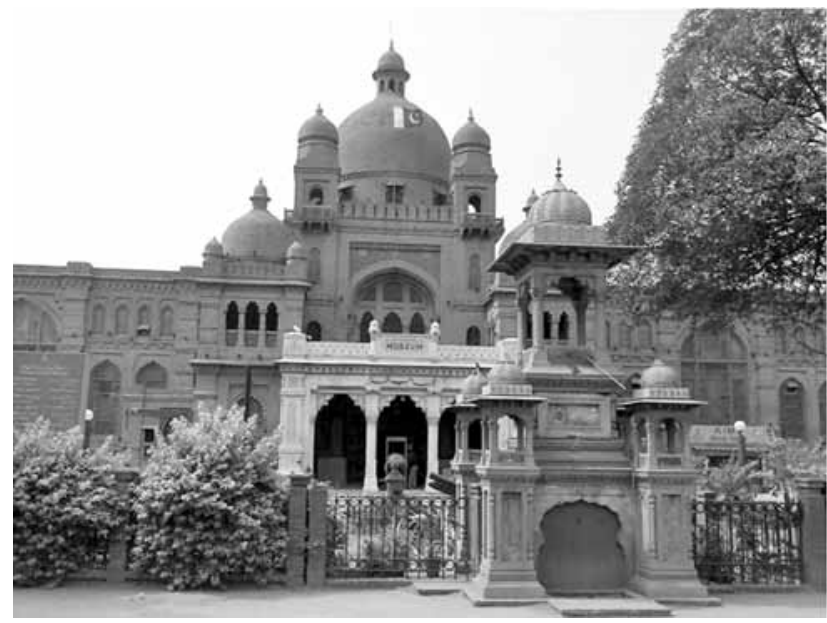

Figure 5: Museum and Mayo School of Arts

Vandal and Vandal (2006: 184) describe the Museum Complex as an iconic building of the city with impressive design and architectural character. In addition to that they have also mentioned the sculptural drinking fountain in the front lawn which is now on the inner edge of the footpath due to the widening of the road.

\section{Victoria Jubilee Hall}

The Victoria Jubilee Hall building was constructed in the 1890 's, and was made possible by the funds collected by the local people. Latif (1892: 273) writes that the inauguration was done by Prince Albert Victor on $3^{\text {rd }}$ February in 1890. This structure is also eclectic in style (Figure 6).

\section{Senate Hall of the Punjab University}

The main building of the Senate Hall was constructed in 1905. With the completion of this building and its adjoining open space, the area became a well-defined public space with a sense of enclosure and architectural character.

Vandal and Vandal (2006: 212) describe the layout and architecture of Senate Hall to be of landmark quality due to the tall clock tower and symmetrical Victorian plan. The front lawn is given a focal point with a centralized fountain which was a common feature in the colonial buildings (Figure 7).

\section{MAIN FEATURES ON ISTANBUL CHOWK}

\section{Zamzama Gun}

The Zamzama Gun forms the focal point of Istanbul Chowk;

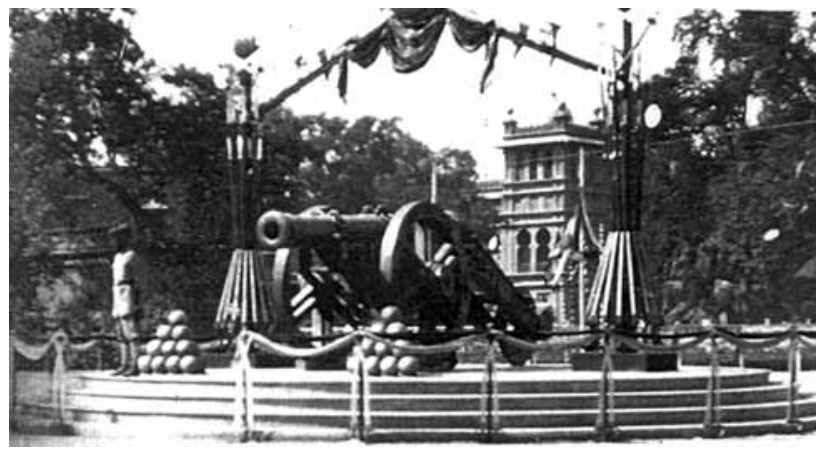

Figure 6: Victoria Jubilee Hall and Zamzama 1890 Source: NCA Archives

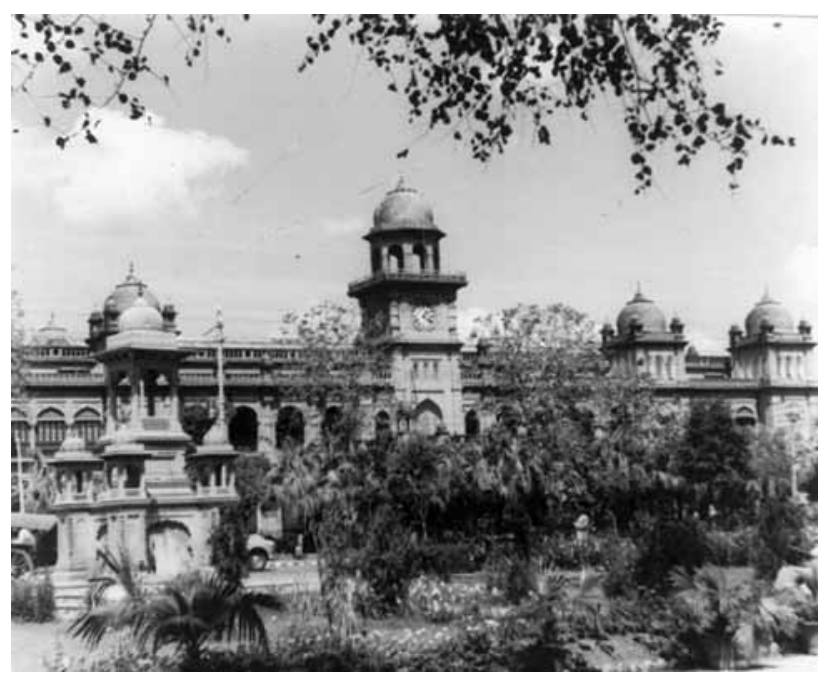

Figure 7: Senate Hall

Source: NCA Archives

also known as Kim's Gun (Reference to Rudyard Kipling's 'Kim'). It is now mounted on a marble clad pedestal in front of the National College of Arts. The gun was restored by 603 combined workshop E.M.E Lahore in October 1976.

There is a mention of this gun in a number of accounts written about this area. Kipling and Thornton (1860: 73) have mentioned the Zamzama Gun as Bhangian-wali Toap (canon attributed to a local tribe). It was the largest gun made in the region in 1761 by Shah Wali Khan, wazir (minister) of Shah Ahmad Durrani for the battle of Panipat (Figure 6).

This gun is also mentioned in the Walker (1989:181). It was initially mounted in front of Delhi Gate (one of the gates of the walled city of Lahore facing east towards Delhi), from where it was removed to be mounted in front of the Lahore Museum in 1860. However, Aijazuddin (2003: 107) 
mentions a different year of the relocation of this gun. $\mathrm{He}$ writes that it was moved in front of the Tollinton Market in 1870 on the visit of Alfred Duke of Edinburgh (the second son of Queen Victoria). He mentions that the gun was further moved in front of the National College of Arts during the early $20^{\text {th }}$ century.

\section{Drinking Fountain (Museum)}

This is a highly ornamental drinking fountain with elaborate architectural details and elements in eclectic style. It is made in red sandstone. It is of considerable scale and is placed along the road in front of the Museum, thus it is very noticeable and forms another focal point of this space. It was built along with the Museum.

\section{Statue of Alfred Woolner, Punjab University, Old Campus}

This memorial statue was designed and made by Gilbert Ledward R.A, a sculptor in Pembroke Walk Studios, Kensington London and dates from $27^{\text {th }}$ May 1937, as mentioned on the archival drawings of the memorial available in Town Hall Archives. It is mounted in front of the Punjab University Senate Hall on a pedestal. In 1951 there was an attempt to remove this statue but luckily it survived (Figure 8).

\section{ISTANBUL CHOWK: SPATIAL IMAGINATION}

In the archival photograph of the Exhibition Road (Figure 9), probably taken from the University's roof top, one can see the Museum building and the Mayo School of Arts. The Museum's drinking fountain and the statue of Alfred Woolner form the focal point of the open space. The entire area is full of trees and there is a strong sense of place because of designed open space between the two facing rows of buildings along the road and well-defined eclectic Colonial architectural character of the buildings surrounding it. The other visually uniting factor in this space is the consistent use of materials, as all the buildings around the Istanbul Chowk are in red brick with fine masonry details. This sense of space is enhanced because of carefully placed fine statue, drinking fountain and the Zamzama Gun. There is a sense of vastness and spatial integrity especially because of absence of any fence between the green space and the road, that is visually and physically uniting the space. The buildings of roughly similar height appear to be providing a rich backdrop to this unified space. The semi-circular gardens, reminiscent of the Victorian planning along with carriageway around them add to the spaciousness. The offset of the buildings from the

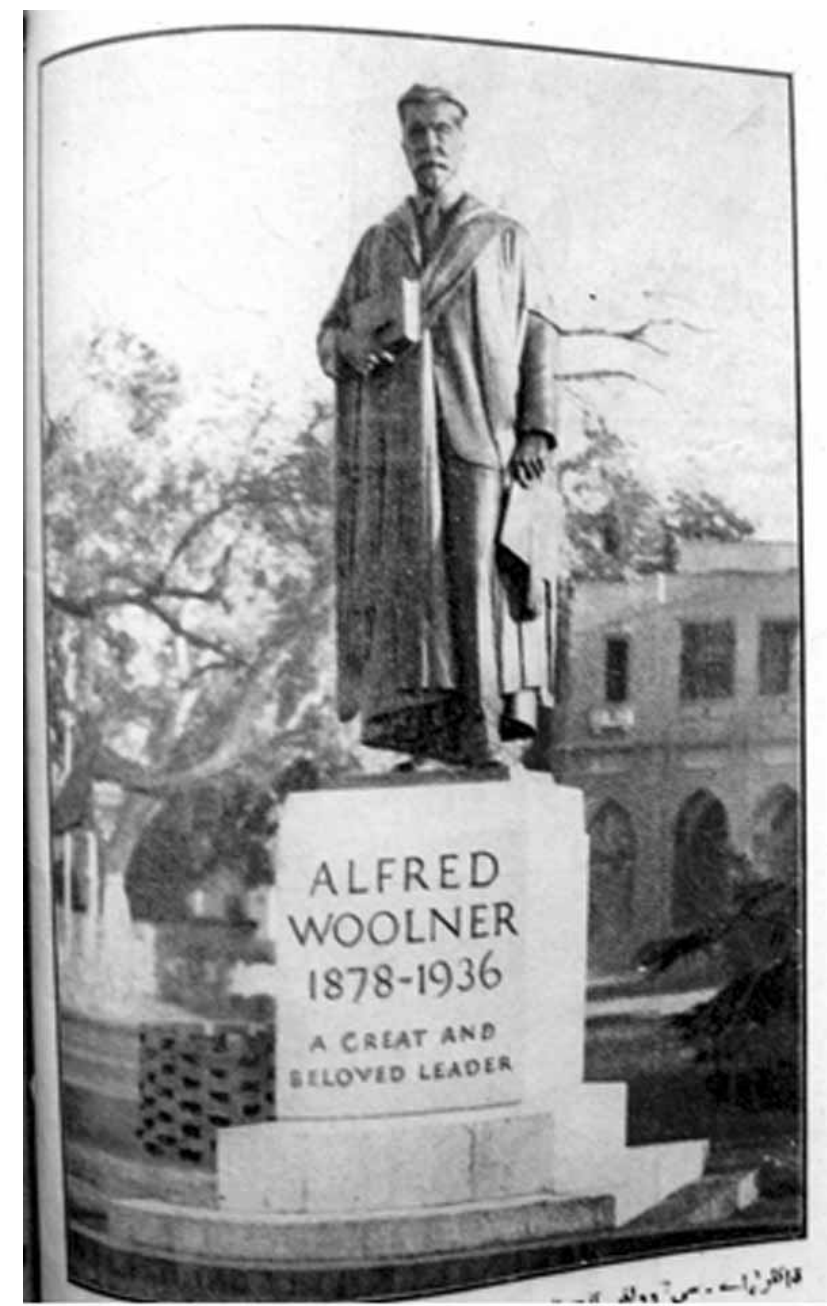

Figure 8: Woolner's Statue Source: NCA Archives

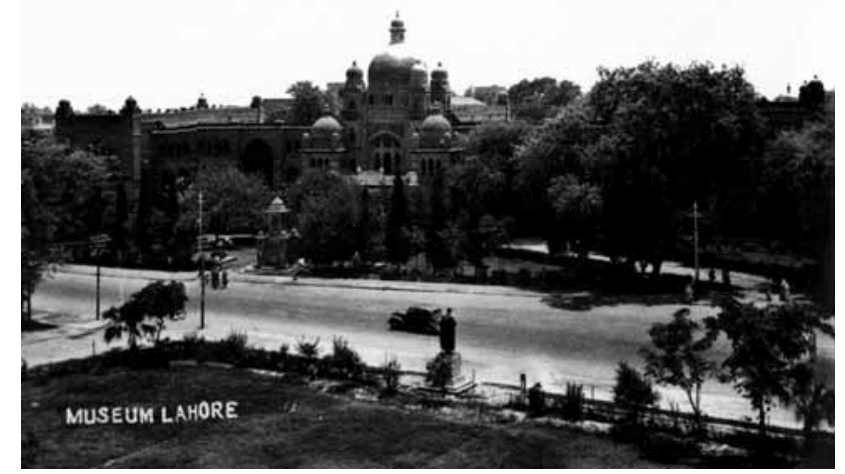

Figure 9: Archival photograph of the area Source: Aijazuddin (2003) 
edge of the road is considerable. The silhouette of the buildings forms a harmonious skyline. The trees are of mix natured with evergreen Cyprus trees along with other leafy varieties, mainly Peepal. A wide footpath for the pedestrians is also visible in the image.

The Mall again widens in front of the Mayo School of Arts with a semi-circular green space in front of the University laboratory. There is an elliptical and a circular space present in the centre of the road. The Zamzama Gun forms the focal point here. The thick and high foliage of Gol Bagh visually encloses the space, containing and defining it (Figure 10). Previously, there was a strong sense of urban axis as the Mall terminated at the Gol Bagh in those days.

\section{ISTANBUL CHOWK: SPIRIT OF THE PLACE}

From the analysis of historical accounts of the British officers, accomplished historians and some memoirs and recollections of residents of the city, it can be constructed that the area of Mall Road around the Istanbul Chowk became the educational and cultural centre of the city.

" One seldom, if ever, hears of Donald Town now, but Anarkali and Naulakha, the two original subdivisions, are still welldefined areas. The social life of old Lahore centred round the now deserted Lower Mall in days not too far distant, when the Police Band played regularly twice a week in the Gol Bagh, then known as the Bandstand Gardens, and the beauty and fashion of the station gathered there to exchange gossip and listen to the music. The bandstand and the masonry promenade are all that now remain as indications of departed glories" Goulding and Thornton (1924: 48).

After the initial estrangement and sense of spatial wonder and awe, the users of the area start relating with it. Stories and legends evolve around the area and the sense of alienation turns into topophilia. This love of place becomes deeply rooted in the lives of its residents and generations of people have stories to tell that revolve around these public places. Because of the Government College, National College of Arts and Punjab University where a majority of the city's youth studied, people feel a very strong connection with this area that they express with great fondness as if they are still living the times. This has rendered the area more like a palimpsest in which the Colonial and the local is almost indecipherably overwritten.

Glover (2008:196) has described this area as modern and multicultural with a sense of cohesiveness and tolerance for diversity. A novel written by Dina Nath during the Colonial

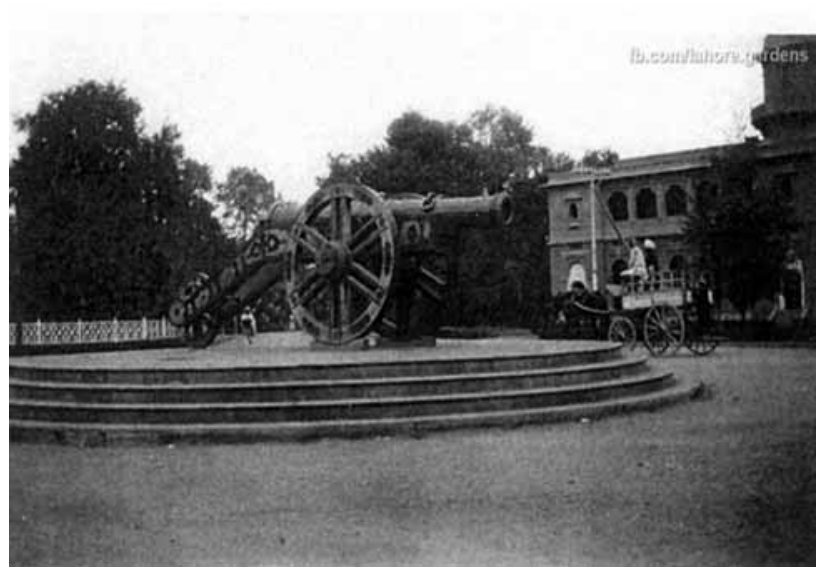

Figure 10: Zamzama with Gol Bagh

Source: Dr. Iqbal Archives

period and referenced by Glover (2008:194) describes the educational environment of this section of the Mall Road:

"Later they stroll beyond the park along Mall Road to Gol Bagh, that rendezvous of students just beyond the Mayo School of Art, where the small groups of youths hover like fairies in celestial regions".

Thus, this area has evolved over time in character and has influenced the intellectual environment of the city. It has served as the centre of Lahore's educational, cultural and literary life. Historically, renowned scholars from the Government College, National College of Arts and Punjab University along with artists, writers and poets from the city used to frequent the nearby Pak Tea House and Coffee House, engaging in never ending scholarly discussions. Major artistic and literary movements of the city have evolved and flourished here, such has been the influence of this inspirational area.

Intizar Hussain, the celebrated short story writer from Lahore, describes Mall Road in his literature as Thandi Sarak (Cool Road), and the reference is used by Suvorova (2011: 210):

"A ladies' cycle had a charm of its own and in the early hours the Mall appeared to be flooded with girls cycling to Government College and the Punjab University."

This is unusual in a way because the public places of Lahore are generally male dominated and women especially young girls do not feel very comfortable using the public space 
because of social norms. The sense of freedom for women expressed in the account is an indication of a tolerant culture based upon gender equality that prevailed in this area and added to the sense of place of the chowk.

\section{ANALYSIS AND DISCUSSION}

\section{Spatial Transformation of Istanbul Chowk}

Since the early $20^{\text {th }}$ century there have been spatial changes and loss of urban heritage in the area. The widening of the road from single lane to three lanes to accommodate the vehicular traffic load is the most obvious one. Design changes in road alignments have been made at points for widening and to make way for through traffic. The major change that impacted upon the spatial integrity of the area took place when the Gol Bagh was intersected and the Mall Road was extended to connect to the Post Master's General's Office. This changed the picturesque urban axis of the Mall once terminating at the Gol Bagh (Figure 11).

A number of walls and fences are put up around the Chowk because of terror threats. The accessibility and physical permeability of the open spaces is affected because of installed iron fences but the visual permeability and spatial integrity of the space was still somewhat intact. But recently

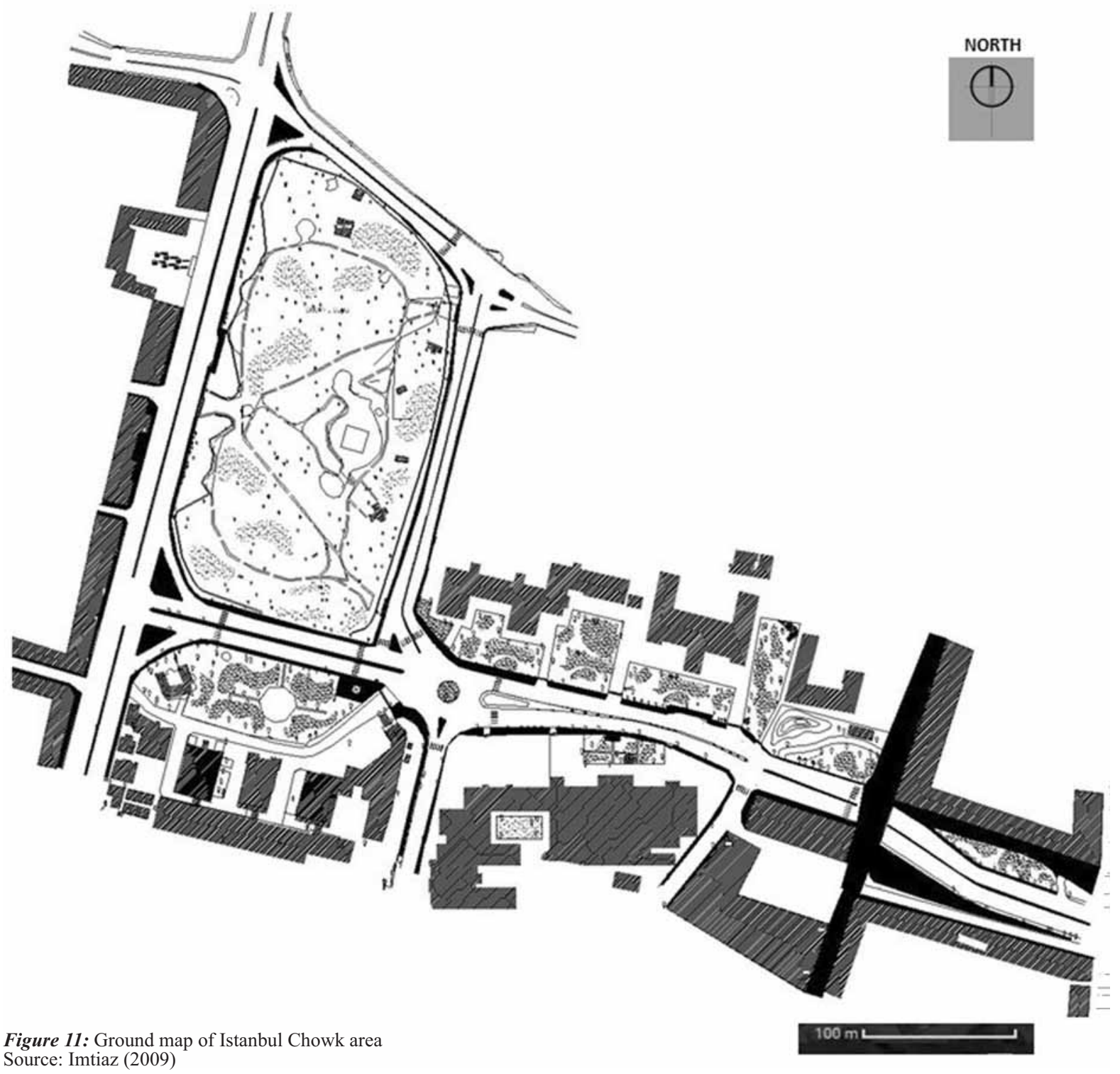

Source: Imtiaz (2009) 
metal sheets were installed along the fence in front of National College of Arts and the Punjab University with razor wires on top, after the attack on Army Public School in December 2014. In the third stage a solid concrete wall has been erected on the side facing the Punjab University in May 2016. This has visually divided the once unified urban space completely. The accessibility and permeability of the institutional spaces is totally compromised. Alfred Woolner's statue today stands outside the University compound because of this new wall (Figures 12 to 14).
There have also been some additions of urban objects to the Istanbul Chowk. One is the installation of M. M. Alam's Saber Jet (he was a PAF pilot who hunted down seven Indian figher planes in the 1965 War) (Figure 15). The other addition is a public sculpture project based upon the idea of pigeonholes to accommodate pigeons present in the Chowk. However the pigeons of Istanbul Chowk have refused to use this new accommodation. This competition project was initiated by Lahore Biennale Foundation.
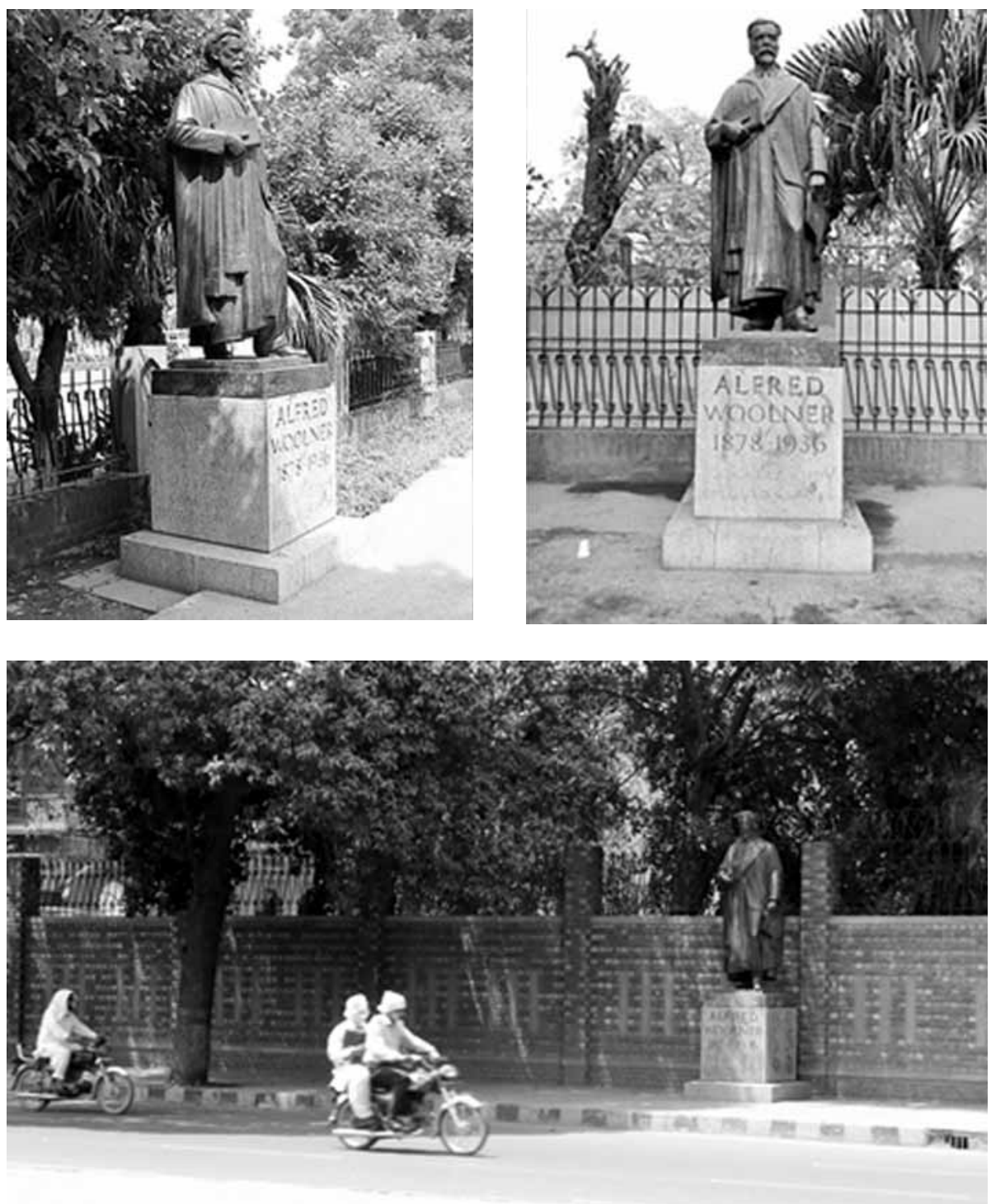

Figure 12 to 14: Three pictures showing the transformation, figure -12 with low fence, figure-13 with high fence and metal sheet, figure-14 with the high wall and fence. 


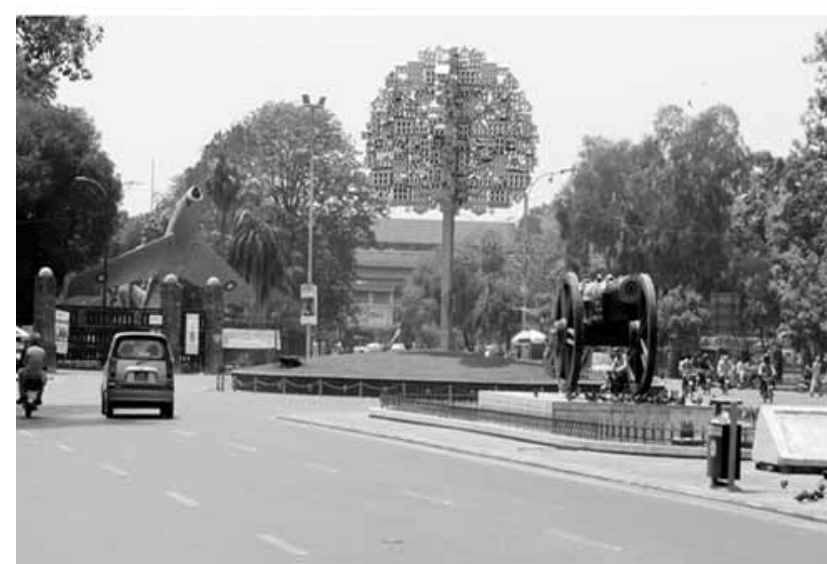

Figure 15: Istanbul Chowk today.

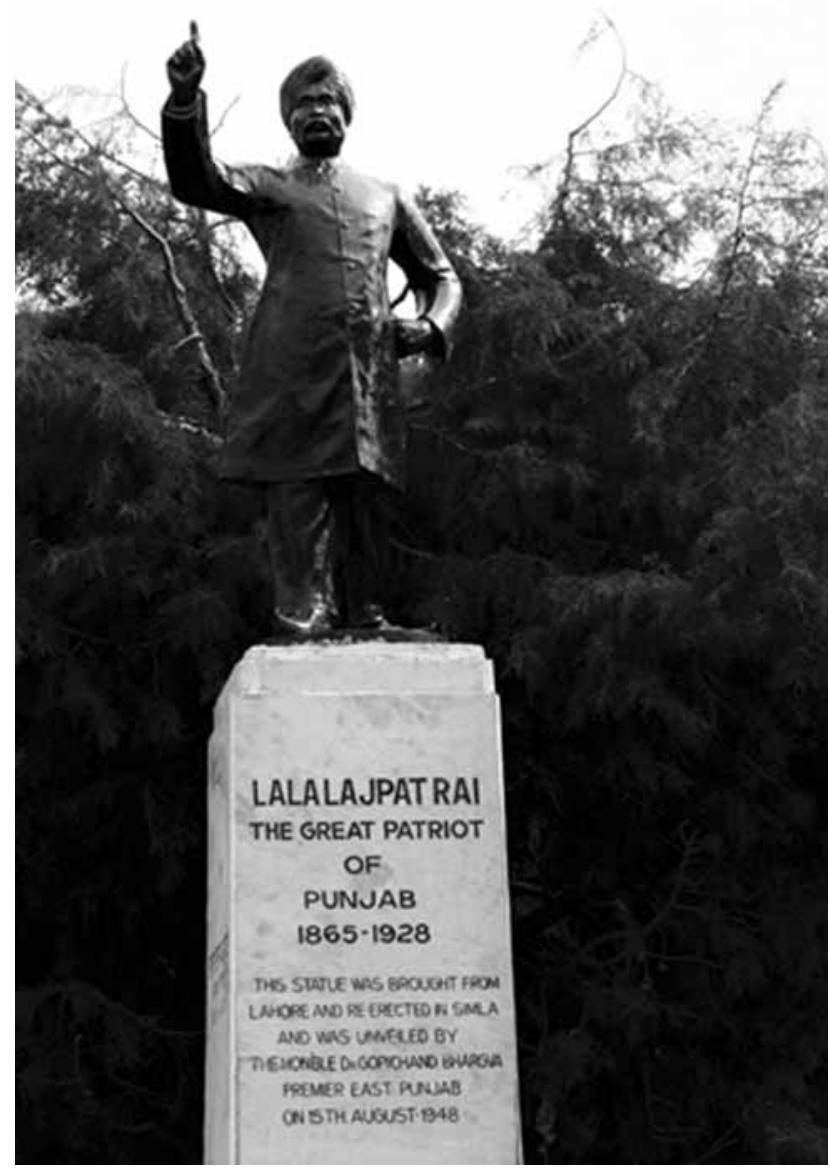

Figure 16: Statue of Lala Lajpat Rai now in Shimla

\section{LOSS OF URBAN HERITAGE ON ISTANBUL CHOWK}

There has also been loss of urban heritage, two British period statues from this area are now missing. One was the statue of Lala Lajpat Rai (1865-1928) (Figure 16) in Istanbul Chowk. For instance, Lala Lajpat while leading a demonstration along with Pandit Madan Mohan Malaviya against the Simon Commission got badly injured during a brutal lathi (baton) charge and succumbed to injuries on November 17, 1928. This statue was somewhere near the Zamzama Gun. It was taken to Shimla in 1948 where it still stands because Lala Lajpat Rai was of Kashmiri descent. Nevile (1993:13), who was a resident of Lahore and a Ravian (Student of Government College, Lahore), mentions this statue with pride in his book on memoirs of Lahore.

The other missing statue from this area is of Sir Ganga Ram, the famous civil engineer and philanthropist of Lahore. Nevile (1993: 13) has also written about this statue with the same sense of pride and he has recognised the contributions of Ganga Ram to the city. The fate of this statue has been narrated by Saadat Hassan Manto (a famous Pakistani writer) in one of his short stories on the frenzy of communal riots of 1947. He describes the way the statue was disgraced with hatred. This statue was removed sometime after partition and was taken to Delhi, India.

\section{CONCLUSIONS AND RECOMMENDATIONS}

The British planners and architects introduced new spatial typologies in the public realm of the sub-continent during the Colonial Period that were inspired from European models. These typologies resulted in an entirely different spatial imagination and left a lasting impact on the urban culture. From narrow streets of the Walled City of Lahore to the fleeting vistas of the Mall Road and vastness of public spaces planned along the main arteries created a completely contrasting experience from the old town. This was a conscious effort by the British planners in order to establish new space syntax to achieve Colonial urban semantics based upon the concepts of Colonial identity, modernity and progress.

Departing from the classical concept of public squares based upon regular geometry, the British planners experimented with informal geometry maintaining a strong axial layout at the same time. They gave these public spaces focal points in the form of sculptures, drinking fountains and memorial status. This was to create recognizable landmarks along with a strong sense of place and identity. They were fully aware 
of the power of space in creating sense of belonging in the shape of topophilia. They also maintained a flexible sense of zoning that helped in developing a distinctive character of public spaces.

Istanbul Chowk is an example of British period spatial imagination having a strong cultural and institutional character that evolved over half a century through incremental addition of buildings of the Museum Complex, the Punjab University and the Town Hall. As a result of the development, a new urban culture emerged in this area that played an important role in forming the modern character and identity of Lahore. It was a completely new spatial typology introduced in Lahore which did not follow the pattern of any of the then existing examples like the nearby forecourt of Wazir Khan mosque in the walled city Lahore or the Hazuri Bagh public open space between Alamgiri Gate of the Lahore Fort and the Badshahi Mosque where Ranjit Singh used to hold his court. These spaces were based on a formal square layout. In the case of Istanbul chowk the space opens up rather gradually to form an elliptical public space enclosed between the Museum and the Mayo School, the Punjab University and the Gol Bagh, with the Zamzama Gun forming the focal centre of this space.

Istanbul Chowk evolved as the first designed British period public space of Lahore. It had a definite sense of enclosure, architectural character and cultural/ educational environment with open green spaces without fences. It served as the interface between the public and the academic institutions. However, this sense of enclosure was ruined when a through road was made in 1961 to connect the Istanbul Chowk and the Post Master General's Office. Moreover the erection of walls and fences between the institutional green spaces and the footpath squeezed the public space and changed the urban character. With the help of comparative analysis based upon cartographic and visual references it can be established that the spirit of the place is still somewhat present but there are numerous spatial changes, additions/alterations and missing objects that have resulted in a weaker sense of place. The pedestrian character and sense of openness is being overshadowed with the road widening and increasing of traffic load.

The changes in the urban character of this section of the Mall Road are somewhat reversible because the form is more or less unaltered except the road through the Nasir Bagh. With little effort it is possible to bring back some of the previous urban character of the place by removing the walls and restoring the public space as a unified area.

There is a need to develop a comprehensive scholarship on history, theory and design of public spaces and its impact on the urban culture in shaping the public places of Lahore to serve as a theoretical framework for Post-Colonial/ post partition spatial imagination and design, especially in the projects related to urban upgradating and regeneration of historic urban centres.

\section{REFERENCES}

Aijazuddin, F. S., 2003, Lahore recollected: An album, Sang-e-Meel Publishers, Lahore.

Glover, W. J., 2008, Making Lahore modern: Constructing and imagining a colonial city, Oxford University Press, Karachi.

Goulding, H. R. and Thornton, T. H., 1924, Old Lahore: Reminiscences of a resident, $2^{\text {nd }}$ edn., Sang-e-Meel Publications, Lahore.

Imtiaz, H., 2009, 'Upgradation Project of the Mall Road, Lahore', NCA, Lahore.

Kipling, J. L. and Thornton, T. H., 1860, Lahore as it was: travelogue, $2^{\text {nd }}$ edn., National College of Arts , Lahore.

Latif, S. M. , 1892, Lahore: Its history, architectural remains and antiquities, $2^{\text {nd }}$ edn., Oriental Publishers and Booksellers, Lahore.

Nevile, P., 1993, Lahore: A sentimental journey, Allied Publishers, New Delhi.

Rehman, A., 2013, Mapping Lahore: Tracing historical geography of a city through maps, Al-Meezan Publishers, Lahore. Suvorova, A. A., 2011, Lahore: Topophilia of space and place, Oxford University Press, Karachi.

Vandal, P. and Vandal, S., 2006, The raj, Lahore, and Bhai Ram Singh, NCA Publication, Lahore.

Walker, G. C., 1989, Gazetteer of the Lahore District: 1883-4, Sang-e-Meel Publications, Lahore. 